\title{
The Cucurbit Pathogenic Bacterium Acidovorax citrulli Requires a Polar Flagellum for Full Virulence Before and After Host-Tissue Penetration
}

\author{
Ofir Bahar, Noam Levi, and Saul Burdman \\ Department of Plant Pathology and Microbiology and The Otto Warburg Minerva Center for Agricultural Biotechnology, \\ The Robert H. Smith Faculty of Agriculture, Food and Environment, The Hebrew University of Jerusalem, P. O. Box 12, \\ Rehovot 76100, Israel
}

Submitted 21 February 2011. Accepted 2 May 2011.

\begin{abstract}
Acidovorax citrulli causes seedling blight and bacterial fruit blotch of cucurbits. Previous reports demonstrated the contribution of type IV pili (T4P) to $A$. citrulli virulence and to systemic infection of melon seedlings. Microfluidic flow-chamber assays demonstrated the involvement of T4P in surface adhesion and biofilm formation, whereas polar flagella did not appear to contribute to either of these features. On the other hand, a transposon mutant impaired in the biosynthesis of polar flagella was identified in screens for reduced virulence of an A. citrulli mutant library. Further characterization of polar flagellum mutants confirmed that $\boldsymbol{A}$. citrulli requires a polar flagellum for full virulence on melon plants. Foliage and stem inoculation experiments revealed that polar flagella contribute to $A$. citrulli virulence and growth in planta at both pre- and post-host-tissue penetration. Interestingly, light microscope observations revealed that almost all $A$. citrulli wild-type cells extracted from the xylem sap of stem-inoculated melon seedlings remained motile, supporting the importance of this organelle in virulence and colonization of the host vascular system. We also report a negative effect of polar flagellum impairment on T4P-mediated twitching motility of $A$. citrulli and discuss a possible co-regulation of these two motility machineries in this bacterium.
\end{abstract}

Flagella are found on the surface of many bacteria, where they are involved in motility, adhesion to and colonization of biotic and abiotic surfaces, and virulence on both animal and plant hosts (Macnab 2003; Moens and Vanderleyden 1996). The role of flagella in virulence has been investigated in several biotrophic and necrotrophic plant-pathogenic bacteria. In most studied biotrophic pathogens, such as Erwinia amylovora (Bayot and Ries 1986), Pseudomonas syringae pv. phaseolicola (Panopoulos and Schroth 1974), P. syringae pv. glycinea (Hattermann and Ries 1989), Ralstonia solanacearum (TansKersten et al. 2001), Xanthomonas campestris pv. campestris (Lee et al. 2003), and X. oryzae pv. oryzae (Feng and Kuo 1975), flagella were shown to be important mainly for invasion of plant tissue. In other words, the main contribution of flagella to pathogenicity is prior to and during plant penetration,

Corresponding author: S. Burdman; Telephone: +972-8-9489369; Fax: +972-8-9466794; E-mail: saulb@ agri.huji.ac.il

* The $e$-Xtra logo stands for "electronic extra" and indicates that four supplementary figures are published online. whereas they were generally not found to be required for virulence at post-penetration stages. One exception for that rule was reported for $P$. syringae pv. tabaci, in which a flagellum mutant showed reduced virulence compared with the wild type, also after direct infiltration into tobacco leaves (Ichinose et al. 2003).

Interestingly, in three studied soft-rot necrotrophic bacteriaPectobacterium carotovorum (Pirhonen et al. 1991), Pectobacterium atrosepticum (Mulholland et al. 1993), and Dickeya dadantii (Antunez-Lamas et al. 2009)—flagellum mutants were impaired in virulence when applied either externally or internally onto host tissue. Hence, the contribution of flagella to virulence varies among different pathogenic bacteria and generalization of their role cannot be made.

The gram-negative, biotrophic, plant-pathogenic bacterium Acidovorax citrulli (A. avenae subsp. citrulli according to the previous nomenclature) causes seedling blight and bacterial fruit blotch (BFB) of cucurbits (Bahar and Burdman 2010; Schaad et al. 2008). A. citrulli strains can be divided into group I and II, which are highly aggressive on melon and watermelon, respectively (Burdman et al. 2005; Walcott et al. 2004). As with many other gram-negative plant-pathogenic bacteria, $A$. citrulli relies on a functional hypersensitive response and pathogenicity (Hrp)-type III secretion system for pathogenicity. Indeed, A. citrulli hrp mutants were shown to be nonpathogenic following various inoculation assays (Bahar and Burdman 2010).

Despite the high economic damage caused by $A$. citrulli (Bahar and Burdman 2010; Schaad et al. 2003), BFB has drawn relatively little attention by the scientific community, and little is known about basic aspects of BFB pathogenesis. A major contribution to basic research of $\mathrm{BFB}$ has been made by the release of the genome sequence of the group II strain AAC00-1, by the Joint Genome Institute, and by optimization of molecular manipulation and inoculation techniques by our and a few other research groups.

We recently reported that the $A$. citrulli group I strain M6 is able to penetrate into and colonize the xylem vessels of melon seedlings, spread through them, and cause seedling death (Bahar et al. 2009). Following a seed transmission-based virulence screen of a transposon mutant library generated in the background of this strain, we identified several virulence-impaired mutants. One of the mutants was impaired in type IV pili (T4P), thin, hair-like appendages found on the bacterial surface at the cell poles. Further studies with this and other T4P mutants demonstrated that T4P are required for twitching motility, and significantly contribute to biofilm formation and virulence of A. citrulli (Bahar et al. 2009). 
Another transposon mutant defective in virulence was found to be impaired in fliR (hereafter M6-fliR mutant). fliR encodes a flagellar biosynthetic protein that is presumably involved in flagellin secretion (Fan et al. 1997). To verify initial findings with M6-fliR, we generated a mutant (named M6-flg) containing an insertion in the flagellin-encoding gene $\mathrm{fliC}$, and a complemented strain (named M6-flgComp) expressing the endogenous fliC gene in the M6-flg mutant. The M6-flg mutant was already tested in microfluidic flow chambers (MFC), microscopic cylindrical chambers that, to some extent, mimic the plant xylem vessels. In these studies, M6-flg did not differ from its parental strain in either surface adhesion or biofilm formation (Bahar et al. 2010).

The lack of differences in adhesion and biofilm formation under flow conditions between the M6-flg mutant and the wild type in MFC experiments, along with the fact that the M6-fliR mutant was impaired in virulence, urged us to determine the role played by polar flagella in virulence of $A$. citrulli. We used different pathogenicity assays to compare the M6-flg mutant with the wild type and to assess the contribution of polarflagella to $A$. citrulli virulence. We show that the single polar flagellum of $A$. citrulli contributes to $A$. citrulli virulence at both

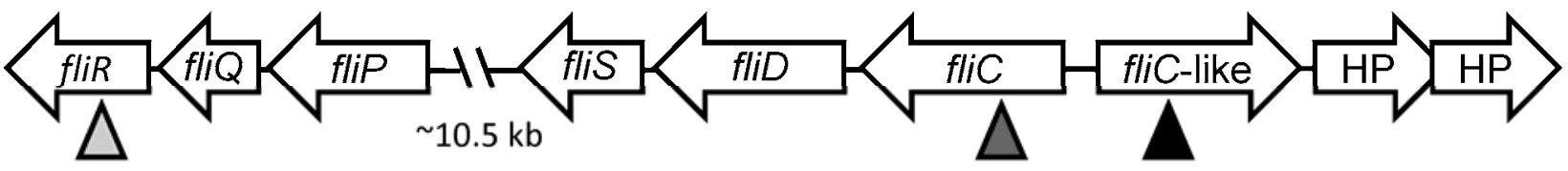

Fig. 1. Schematic organization of flagellum-related genes according to the annotation of Acidovorax citrulli AAC00-1 chromosome (NC_008752). Gene description from left to right: $f l i R$, Aave_4383; fliQ, Aave_4384; fliP, Aave_4385; fliS, Aave_4398; fliD, Aave_4399; fliC, Aave_4400; fliC-like, Aave_4401; hypothetical protein (HP), Aave 4402; hypothetical protein containing a SAM-binding motif, Aave 4403. The 10.5-kb gap between fliP and fliS contains a cluster of 13 additional flagellar-related genes. Triangles below arrows show the site of mutations in strain M6: light gray, M6-fliR mutant; dark gray, M6-flg mutant (fliC); black, mutation in the fliC-like gene (Aave_4401) that did not result in loss of motility and flagellin production.

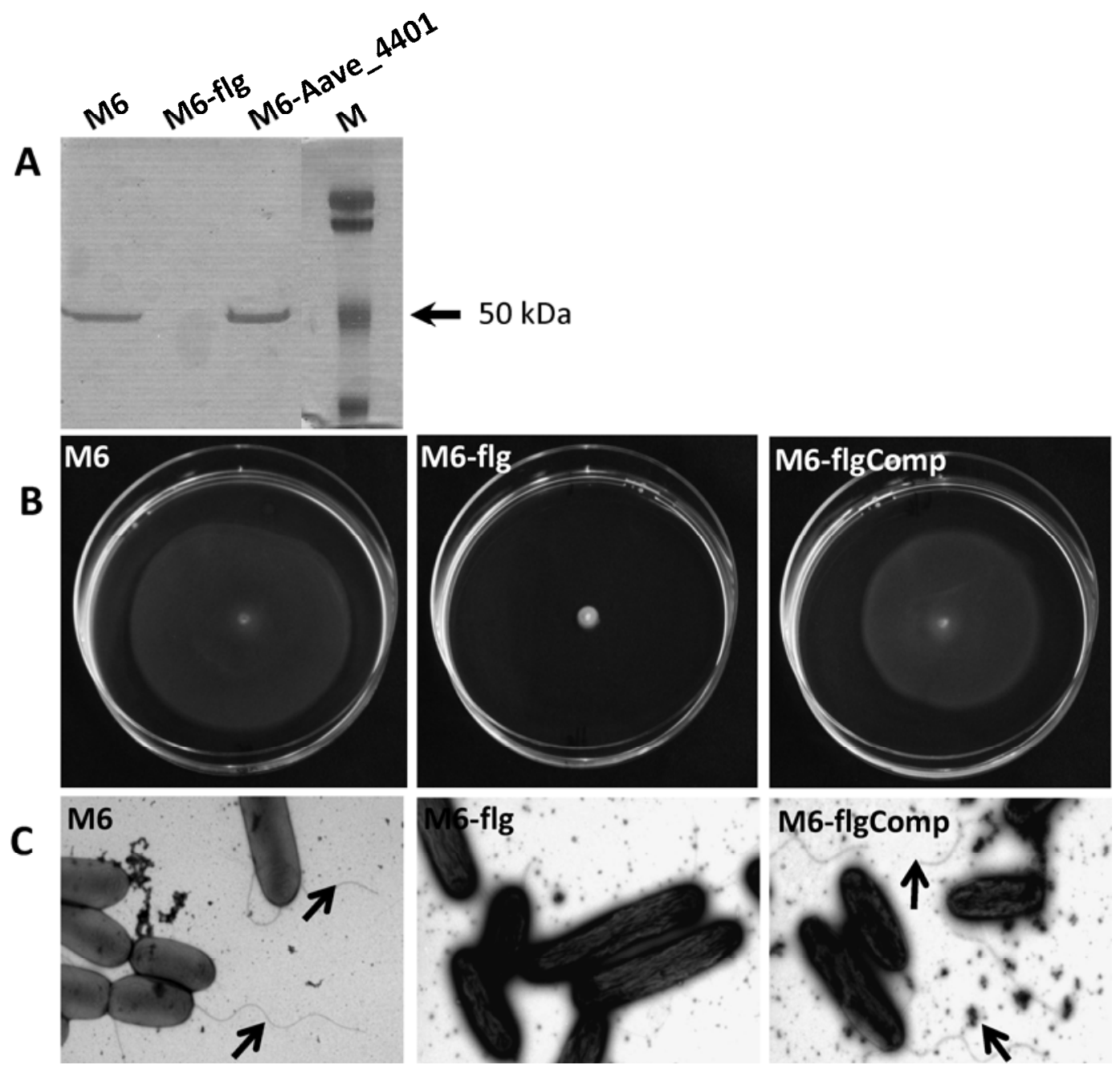

Fig. 2. Polar flagellum and swimming motility in the Acidovorax citrulli wild type and M6-flg $(f l i C)$ mutant. A, Sodium dodecyl sulfate polyacrylamide gel electrophoresis of flagellin preparation from M6, wild type; M6-flg, M6 mutated in gene fliC (Aave_4400); and M6-Aave_4401, M6 mutated in the fliC-like copy (Aave_4401). M, Bio-Rad protein ladder (Bio-Rad Laboratories, Inc.). Flagellin was visualized by Coomassie brilliant blue staining. In strains M6 and in M6 mutated in Aave_4401, the only observed band migrated as expected based on the predicted size of A. citrulli flagellin (approximately $49.4 \mathrm{kDa}$ ). Mutant M6-flg does not produce flagellin. B, Motility assays in soft (0.3\%) agar plates. Strains (from left to right): M6, M6-flg, and M6-flgComp (M6-flg carrying native fliC in plasmid pBBR-MCS/flg-comp). C, Transmission electron microscope verification of presence or absence of polar flagella. Full-length flagella (arrows) can be seen in strains M6 (left) and M6-flgComp (right), while a short and truncated filament (100 to $300 \mathrm{~nm}$ ), presumably the flagellar hook, is seen in mutant M6-flg (middle). 


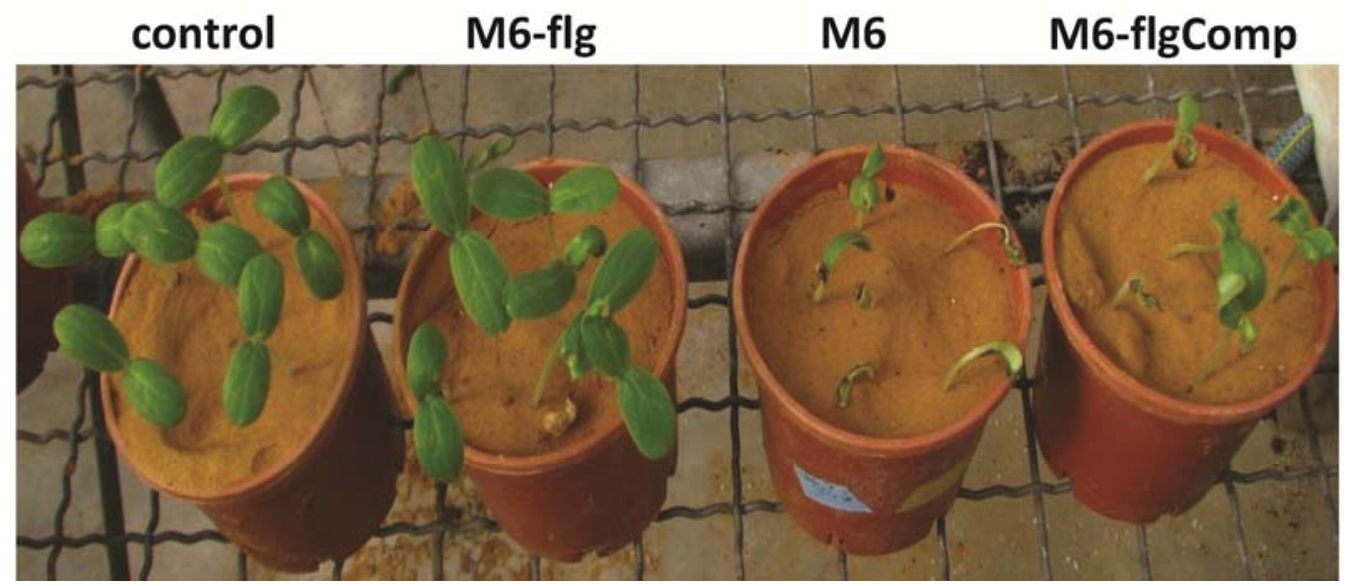

Fig. 3. Seed transmission assays. Melon seed were suspended in $10^{6}-\mathrm{CFU} / \mathrm{ml}$ bacterial suspensions for $2 \mathrm{~h}$ and then sown in pots containing sand. Left to right: control, noninoculated seed; M6-flg, flagellin mutant; M6, wild type; M6-flgComp, complemented strain. Seedlings were photographed 10 days after inoculation and sowing. Pictures of representative pots (out of four per treatment) from one experiment of three with similar results.
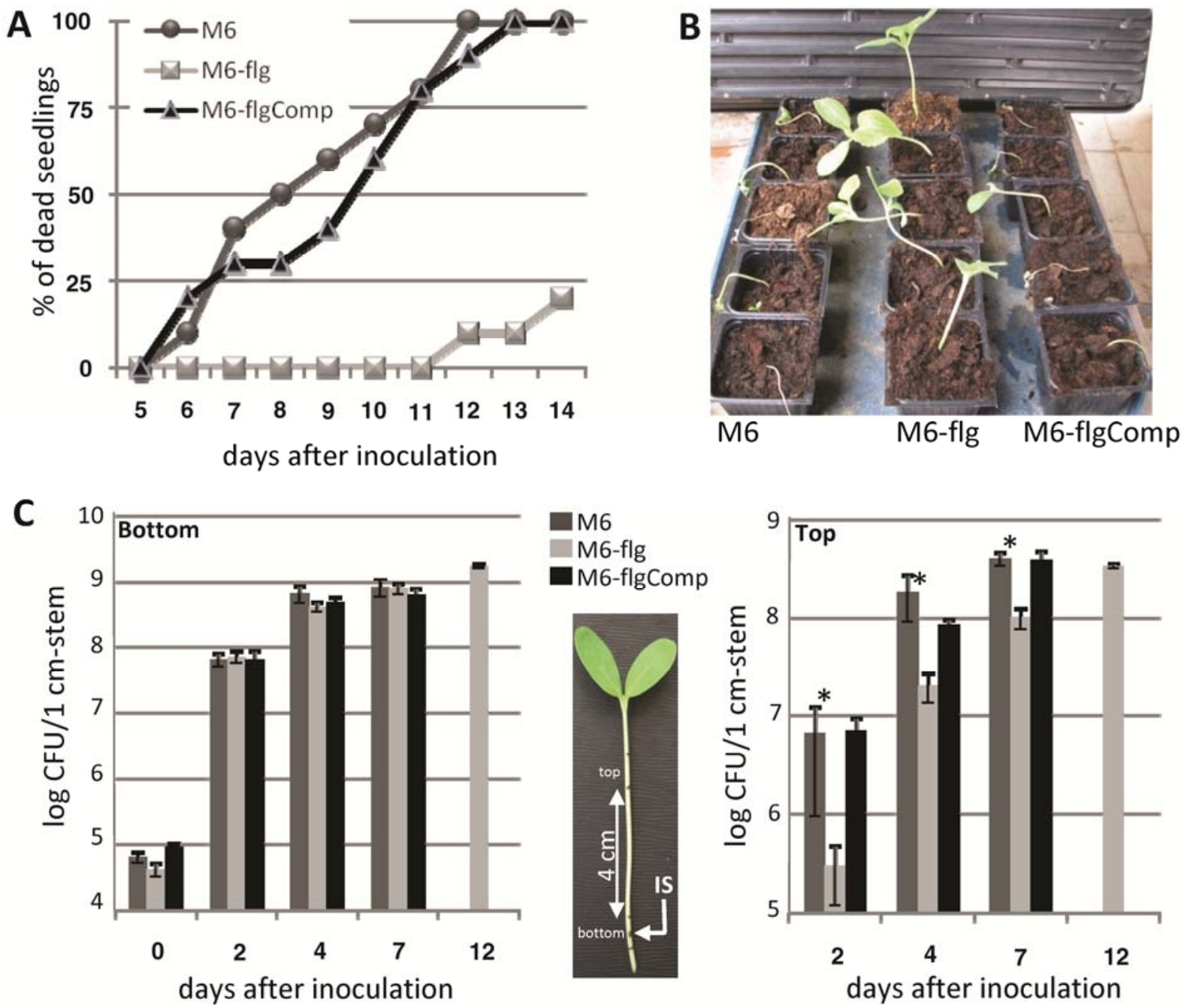

Fig. 4. Stem inoculation of melon seedlings. Eight-day-old melon seedlings were stem inoculated by placing a 5 - $\mu 1$ droplet with bacteria at $5 \times 10^{8} \mathrm{CFU} / \mathrm{ml}$ at the base of the stem and passing a needle thorough the droplet and the stem. Droplets were removed immediately after inoculation. A, Percentage of dead seedlings over time: circle, wild type M6; square, M6-flg mutant; triangle, M6-flgComp strain. B, Pictures taken from representative treatments at 10 days after inoculation (dai). C, Bacterial concentrations in planta (mean \pm standard error) of strains M6 (dark gray), M6-flg (light gray), and M6-flgComp (black) at the bottom (around the inoculation site; left) and top (right) parts of the stem. In the seedling picture, the inoculation site (IS) is indicated. Bottom and top parts have a length of $1 \mathrm{~cm}$, and the distance between them is $4 \mathrm{~cm}$. Bacterial concentrations were not determined for strains M6 and M6-flgComp at 12 dai, because seedlings inoculated with these strains were dead or at advanced wilting by this time. Time points marked with an asterisk indicate significant $(P=$ 0.05) differences between wild-type M6 and mutant M6-flg. No significant differences were observed between strains M6 and M6-flgComp. Data are from one experiment out of three with similar results. 
both pre- and post-host-tissue penetration stages following both foliage and stem inoculation. It is also shown that impairment of polar flagella negatively affects T4P-mediated twitching motility, which could also contribute to the reduced virulence of the polar flagellum mutants.

\section{RESULTS}

Identification of a polar flagellum mutant (M6-fliR) with attenuated virulence.

Our first evidence for the involvement of polar flagella in $A$. citrulli virulence was obtained from seed transmission virulence screens of a transposon mutant library generated in the background of $A$. citrulli M6. In these screens, we identified mutant M6-495, which showed reduced virulence on melon relative to wild-type M6. Sequence analysis of this mutant showed a single insertion of the transposon inside $f l i R$, which encodes a flagellar assembly protein (gene Aave_4383, according to the annotation of the AAC00-1 genome; GenBank NC_008752) (Fig. 1). Therefore, the M6-495 mutant was renamed M6-fliR. Although this mutant retained pathogenic ability, it was clearly attenuated in virulence relative to the wild type in seed transmission assays (Supplementary Fig. 1). Light microscopy observations and motility assays in soft agar plates confirmed the loss of flagellum-mediated motility in this mutant (not shown).

The $A$. citrulli chromosome contains two genes homologous to fliC but only one of them is required

for flagellin production and motility.

To further verify the involvement of polar flagella in $A$. citrulli virulence, a mutation in $\mathrm{fliC}$, which encodes the flagellin subunit, was created by gene disruption. According to the annotation of the AAC00-1 genome, and similar to other bacteria such as Sinorhizobium meliloti, Campylobacter coli, Helicobacter pylori, and H. mustelae (Guerry et al. 1991; Josenhans et al. 1995; Pleier and Schmitt 1989), A. citrulli bears two fliC copies, Aave_4400 and Aave_4401 (Fig. 1). These two genes are predicted to encode proteins with the same number of amino acids (492 amino acids) and are 88\% identical on the basis of their predicted amino acid sequence.

Two $\mathrm{fliC}$ copies are also present in strain M6 and, because the mutagenesis vector used to create the flagellin mutant was based on a region that is $100 \%$ identical between the two copies (Bahar et al. 2010), two distinct mutants were obtained, one for each copy, as revealed by Southern blot analysis (not shown). Interestingly, the mutant impaired in the Aave_4401 homolog gene showed flagellin production and motility similar to that of wild-type M6, whereas the mutant impaired in the Aave_4400 homolog gene did not produce polar flagella and was completely nonmotile (Fig. 2A and B). We then concluded that the latter gene is $f l i C$, encoding flagellin, and the corresponding mutant was named M6-flg. The second gene was named fliC-like (Fig. 1).

Complementation of mutant M6-flg with plasmid pBBRMCS/flg-comp, containing the M6 fliC gene (strain M6flgComp), restored polar flagellum-mediated motility, as revealed by light microscope observations and motility assays on soft agar (Fig. 2B). Sequence analysis of the M6 fliC gene, including $333 \mathrm{bp}$ preceding the putative start codon, revealed that it is $100 \%$ identical to the fliC gene (Aave_4400) of the group II strain AAC00-1.

Transmission electron microscope (TEM) observations were also carried out to assess the presence or absence of polar flagella in the different strains. As expected, most M6 and M6-
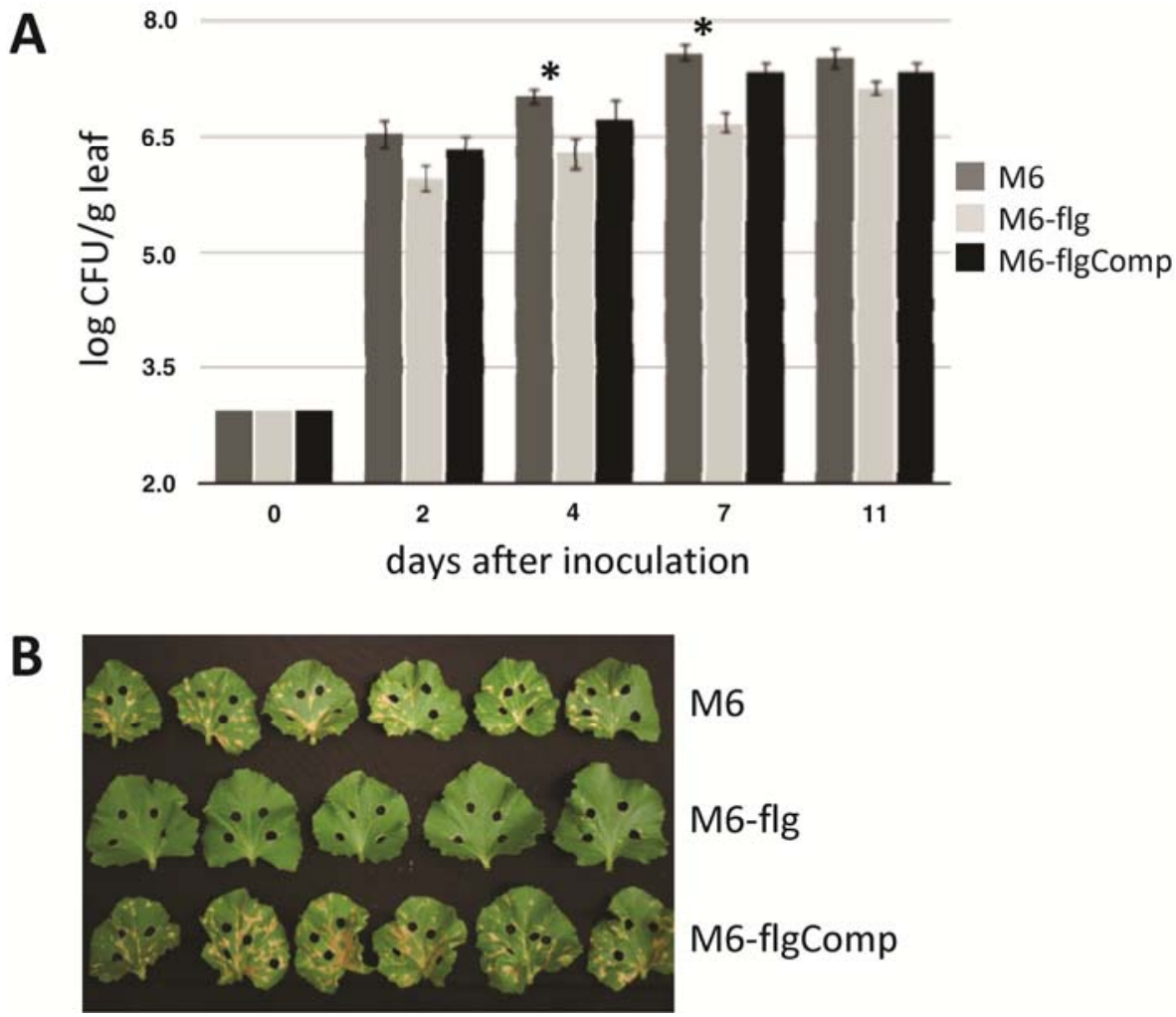

Fig. 5. Foliage inoculation of melon seedlings using vacuum infiltration. Three-week-old melon seedlings were vacuum infiltrated with $10^{2}$-CFU/ml bacterial suspensions. A, Bacterial growth in planta of strains M6 (dark gray), M6-flg (light gray), and M6-flgComp (black). Bacterial concentrations in planta (mean \pm standard error) were monitored over 11 days by sampling leaf discs and dilution plating on nutrient agar plates. Time points marked with an asterisk indicate a significant $(P=0.05)$ difference between wild-type M6 and mutant M6-flg. No significant differences were observed between strains M6 and M6-flgComp. B, Illustration of symptom development in true leaves following vacuum infiltration. Pictures were taken 11 days after inoculation. Data are from one experiment out of two with similar results. 
flgComp cells possessed a single, full-length polar flagellum, whereas only a short and truncated filament, 100 to $300 \mu \mathrm{m}$ long (likely the flagellar hook, which is not composed of flagellin), were seen on M6-flg cells (Fig. 2C).

\section{The flagellin mutant M6-flg shows reduced virulence relative to the wild type in seed-transmission assays.}

In agreement with the observed reduced virulence of mutant M6-fliR in seed-transmission assays with melon, mutant M6flg was also impaired in virulence in these assays. In contrast, strain M6-flgComp showed wild-type levels of virulence (Fig. 3). To determine whether the reduced virulence of strain M6flg is due, at least in part, to reduced seed adhesion relative to the wild type, seed were inoculated with both strains and bacteria were extracted and quantified by dilution plating. Strains M6 and M6-flg did not differ significantly from each other in bacterial concentration in inoculated seed $(P=0.05)$ (not shown), implying that the role of polar flagella in virulence in seed transmission assays takes place after adhesion to the seed.

\section{The M6-flg mutant is less virulent}

than the wild type in stem-inoculation assays.

A. citrulli possesses the ability to colonize the xylem vessels of melon seedlings (Bahar et al. 2009). We assessed whether polar flagella are important for virulence in standard steminoculation assays in which a $5-\mu l$ droplet of the bacterial suspension is placed at the base of the seedling stem and a needle is passed through the droplet and the stem to introduce the bacteria inside the stem. The first experiments with bacterial suspensions of $10^{8} \mathrm{CFU} / \mathrm{ml}$ revealed that the M6-flg mutant was impaired in virulence relative to the wild type: while inoculation with the wild type resulted in approximately $95 \%$ dead seedlings 10 days after inoculation (dai), the M6-flg mutant yielded only $30 \%$ dead seedlings after the same time. In these experiments, the inoculum droplets were not removed from the stem after bacterial injection. Therefore, we suspected that this technique conferred an initial advantage to motile wild-type over nonmotile M6-flg cells. Indeed, bacterial counts from stem tissue at the inoculation site $2 \mathrm{~h}$ after inoculation (hai) revealed significantly $(P=0.05)$ higher $\mathrm{CFU}$ values for the wild type relative to the mutant (not shown).

We then performed new stem inoculation assays using a higher inoculum concentration $\left(5 \times 10^{8} \mathrm{CFU} / \mathrm{ml}\right)$ but removing the inoculum droplets immediately after needle injection. Using this technique, similar CFU counts were recorded for wild-type and mutant M6-flg around the inoculation site at 2 hai (Fig. 4C). Nevertheless, the mutant remained clearly impaired in virulence relative to the wild type and the complemented strain, as could be observed by assessment of disease severity in the following days. Although most M6- and M6-flgComp-inoculated seedlings showed severe disease symptoms (including necrosis in cotyledons, severe seedling wilt, and death) at 6 dai, a few (approximately 20\%) M6-flg-inoculated seedlings showed only moderate symptoms in cotyledons by the same time. Moreover, most M6- and M6-flgComp-inoculated seedlings were dead 10 dai, whereas no seedling inoculated with mutant M6-flg died by the same time (Fig. 4A and B). These results imply that polar flagella have a role in virulence of $A$. citrulli after penetration into the xylem vessels.

\section{Mutant M6-flg possesses reduced}

xylem-establishment ability as compared with the wild type.

To examine whether disease severity correlates with bacterial growth in planta, we assessed bacterial levels in plant stems at different times, both around the inoculation site and in the upper part of the seedlings ( $4 \mathrm{~cm}$ above the bottom part) (Fig. 4C).
At the inoculation site, no significant differences in bacterial counts between wild-type and mutant M6-flg were observed (Fig. 4C). In contrast, differences between strains in the upper part of the seedling remained significant $(P=0.05)$ at later stages of these experiments, clearly indicating that the M6-flg mutant is impaired in systemic colonization relative to the wild type and the complemented strain (Fig. 4C). Interestingly, by the end of these experiments, at 12 dai, the M6-flg mutant reached the levels of colonization observed for the wild-type and complemented strain at 7 dai (Fig. 4C); however, the percentage of seedling death in M6-flg-treated seedlings did not increase as a result of the increase in the bacterial population.

In $R$. solanacearum, it was shown that bacteria shear off their polar flagella after invasion of xylem vessels (Tans-Kersten et al. 2001). To examine whether A. citrulli behaves in a similar manner, we extracted xylem sap from inoculated seedlings and determined both bacterial concentration and the percentage of motile cells. In accordance with the observed differences in seedling death and bacterial counts, wild-type M6 was found in the xylem sap at much higher levels than mutant M6-flg. Whereas wild-type cells were detected at concentrations of approximately $10^{5}$ to $10^{6} \mathrm{CFU} / \mathrm{ml}$ of xylem sap 4 dai, M6-flg cell counts reached $10^{3}$ to $10^{4} \mathrm{CFU} / \mathrm{ml}$ at the same time point. In some experiments, the other polar flagellum mutant, M6fliR, was also assessed, showing concentrations similar to those of M6-flg. In contrast, the fliC-complemented strain M6flgComp showed cell concentrations similar to those of the wild type. Interestingly, differences in cell concentration among strains generally correlated negatively with the amount of sap that could be extracted from inoculated seedlings (not shown). Namely, the lowest volumes of extracted sap were generally associated with the highest bacterial concentrations in the sap, implying a possible link between cell concentration and xylem sap blockage.

We also assessed swimming ability of $A$. citrulli cells in the xylem sap up to 5 days after stem inoculation by extracting xylem sap from infected plants and immediately observing sap samples under a light microscope. To our surprise, in contrast to observations with $R$. solanacearum, the great majority (almost $100 \%$ ) of A. citrulli M6 and M6-flgComp cells extracted from the xylem saps remained fully motile during this period of time. As expected, no motility was observed for the polar flagellum mutants M6-flg and M6-fliR.

\section{Mutant M6-flg is impaired in growth in planta relative to the wild type following foliage inoculation.}

We also assessed the importance of polar flagella in foliage inoculation experiments using three different settings: i) dipping the plants inside bacterial suspensions at $10^{6} \mathrm{CFU} / \mathrm{ml}$ and keeping them in a high-humidity regime for $24 \mathrm{~h}$, ii) dipping plants in the same way but without maintaining high humidity, and iii) inoculating foliage by vacuum infiltration at $10^{2}$ $\mathrm{CFU} / \mathrm{ml}$. We assumed that vacuum inoculation experiments will help in elucidating whether polar flagella are important for virulence once the bacteria are inside the leaf apoplast, while foliage inoculation without vacuum will help in assessing the contribution of polar flagella at preinvasion stages.

In all settings and at all sampling days, both M6 and M6flgComp strains propagated to higher levels than the M6-flg mutant (Fig. 5A; Supplementary Fig. 2). Although differences were not significant at all time points, in accordance with other virulence assays, these experiments strengthened the idea that M6-flg possesses reduced virulence compared with the wild type. Differences in growth in planta correlated with symptom development: whereas both M6 and M6-flgComp showed typical necrosis on true leaves, the M6-flg mutant hardly caused any visible symptom (Fig. 5B, vacuum infiltration). In all ex- 
periments, the wild type and the complemented strain did not differ significantly from each other at any time tested.

Altogether, foliar inoculation experiments indicate that $A$. citrulli requires polar flagella for full virulence both before and after tissue penetration. Importantly, in vitro growth curves in either rich (nutrient broth [NB]) or minimal (M9) media revealed that M6-flg is not affected in its growth rate compared with the wild type (Supplementary Fig. 3); thus, differences in growth in planta and in disease symptom induction ability between the mutant and the wild type cannot be attributed to a general impairment affecting growth ability in the mutant.

We also compared between wild type and polar flagellum mutants for their hypersensitive response (HR)-inducing ability in non-host tomato leaves, after syringe infiltration with $10^{8}-\mathrm{CFU} / \mathrm{ml}$ bacterial suspensions. The wild type and mutants M6-flg and M6-fliR did not differ in their ability to induce HR necrosis, which was visible $24 \mathrm{~h}$ after inoculation (hai), and became fully necrotic 48 hai (Supplementary Fig. 4). No differences between strains were observed after inoculation with lower bacterial concentrations $\left(10^{5}, 10^{6}\right.$, and $\left.10^{7} \mathrm{CFU} / \mathrm{ml}\right)$ (not shown).

\section{Impairment of flagellin synthesis inhibits twitching motility but not biofilm formation.}

T4P-mediated twitching motility typically generates visible haloes surrounding $A$. citrulli colonies growing in solid media (Bahar et al. 2009). When streaking mutant M6-flg on nutrient agar (NA) plates, we noticed that this mutant appears to be delayed in the production of twitching haloes relative to wildtype M6 (Fig. 6A). Quantitative assessment of this trait 48 and $72 \mathrm{~h}$ after streaking revealed that, indeed, colonies of the mutant develop twitching haloes at a significantly $(P=0.05)$ slower rate than the wild type (Fig. 6B). The fliR mutant was also significantly $(P=0.05)$ delayed in this trait relative to the wild type but not to the same extent as M6-flg. Complementation of the M6-flg mutant (strain M6-flgComp) partially restored the wild-type phenotype, supporting the idea that twitching inhibition in the tested mutants is associated with the impairment of polar flagella (Fig. 6).

We examined whether the delayed twitching ability of mutants M6-flg and M6-fliR was due to lack of T4P production. TEM observations of 48-h-old cells did not reveal apparent differences in T4P production among the wild type and polar flagellum mutants, because they all had similar amounts of T4P on the cell poles (not shown).

We also assessed whether mutant M6-flg is impaired in biofilm formation on glass and on polystyrene surfaces. In accordance with our previous observations inside MFC (Bahar et al. 2010), these classical in vitro assays did not reveal any difference in biofilm formation between M6-flg and the wild-type strain (Fig. 7A and B). In agreement with these assays, and despite the aforementioned reduced ability of mutant M6-flg to establish in xylem vessels in stem inoculation assays, scanning electron microscope (SEM) observations revealed that mutant M6-flg retains the ability to colonize and form biofilm in xylem vessels of melon seedlings (Fig. 7C).

\section{DISCUSSION}

Flagella are important for host penetration and colonization of several plant- and animal-pathogenic bacteria. At the early stages of infection, flagella facilitate the movement of the cell toward or away from favorable and repelling niches, respectively. Often, they also confer adhesive functions that expedite the attachment of the bacterium to different surfaces (Moens and Vanderleyden 1996). At more advanced stages of infection, some pathogenic bacteria downregulate motility and even shear off their flagella that often appear not to play a crucial role in virulence at post-host-penetration stages (Akerley et al. 1995; Manson et al. 1998; Tans-Kersten et al. 2001).

Previous reports supporting the notion that flagella act mainly at the early stages of infection suggested an interaction

A
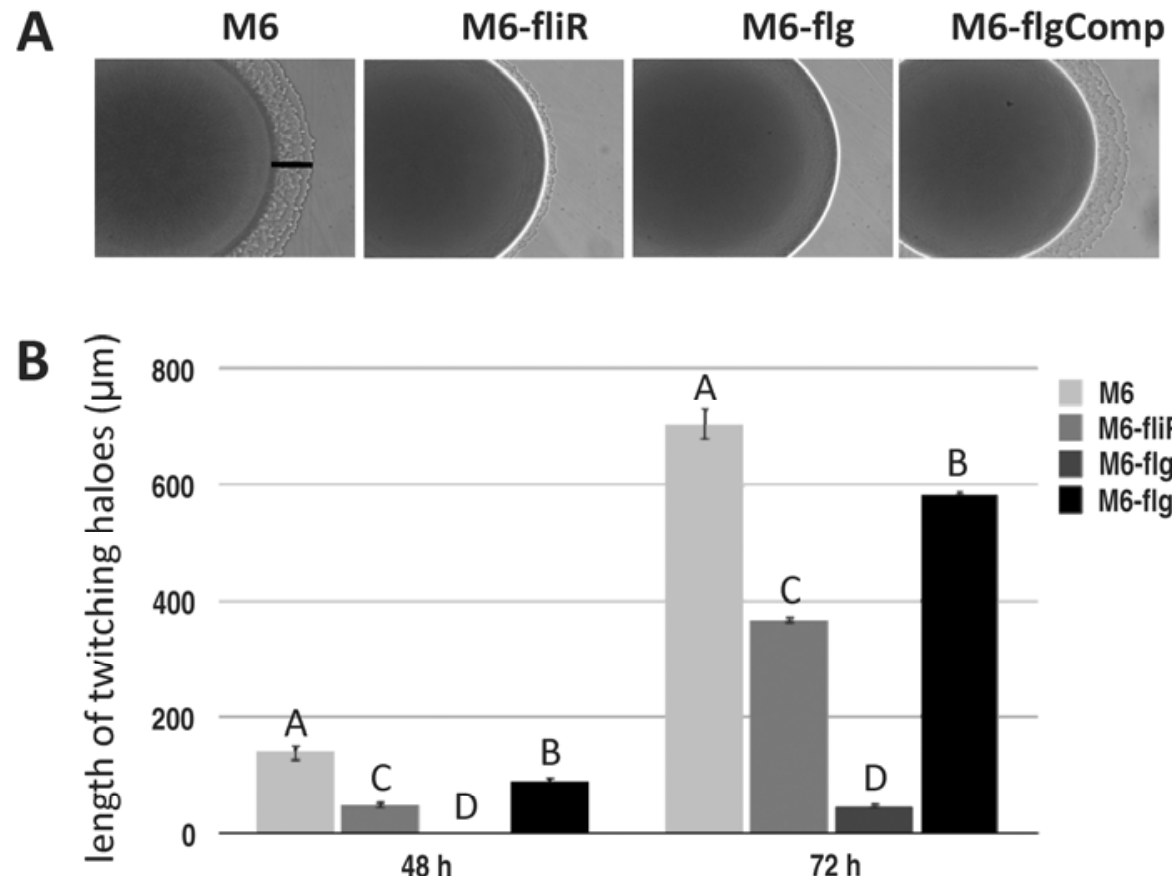

हᄐ

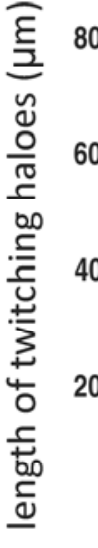

800
600
400
200
0
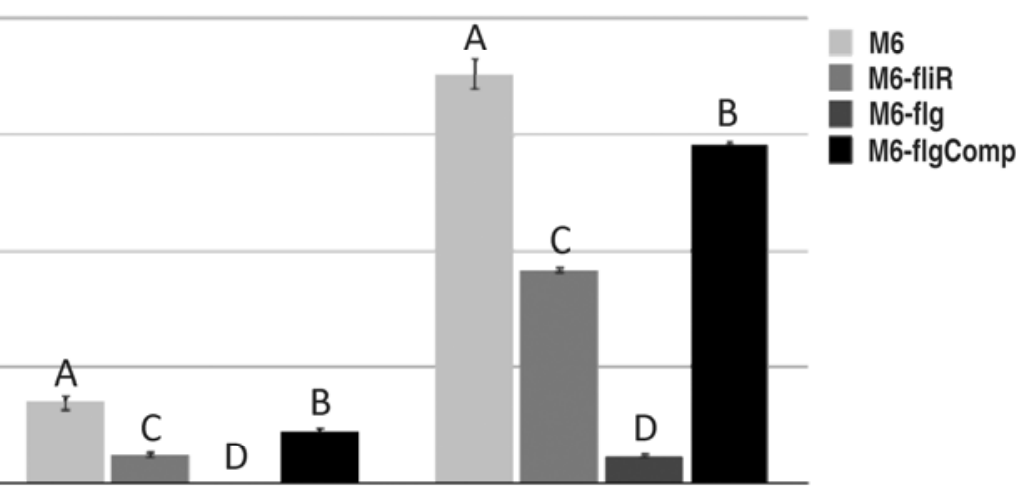

$48 \mathrm{~h}$

hours after streaking

Fig. 6. Impairment of polar flagellum production affects twitching motility in Acidovorax citrulli. Strains were plated on nutrient agar plates and twitching haloes were measured 48 and $72 \mathrm{~h}$ after plating. A, Pictures of strains M6, M6-fliR, M6-flg, and M6-flgComp taken $48 \mathrm{~h}$ after plating. Black line in M6 illustrates the length of the twitching halo. B, Data (mean \pm standard error) of twitching halo lengths for the same strains, 48 and $72 \mathrm{~h}$ after plating. Different letters indicate significant $(P=0.05)$ differences among strains in each time point. Data are of one experiment of two with similar results. 
with the Hrp-type III secretion system (TTSS). The flagellar system itself acts as a secretion apparatus that secretes flagellin subunits in a similar manner as the Hrp-TTSS, both structurally and functionally (Hueck 1998; Macnab 1999). It has been suggested that, when both systems are present, they counter-regulate each other, and that some pathogenic bacteria must switch off their flagellar system in order to be fully virulent (Ottemann and Miller 1997). This is in accordance with the theory by which the flagellar system is required for the initial stages of infection, whereas the Hrp-TTSS is crucial for later stages, when intimate contact between the pathogen and host cells is established (Josenhans and Suerbaum 2002; Ottemann and Miller 1997).

However, functional flagella are also required by some pathogenic bacteria at the advanced stages of infection. Interestingly, most studies with biotrophic plant-pathogenic bacteria suggested that flagella do not substantially contribute to virulence after host penetration whereas, in the case of necrotrophic pathogens, flagella were shown to be needed for full virulence, also after host penetration (discussed above). It is possible that maceration of the plant tissue caused by enzymes released by necrotrophic bacteria generates a more suitable niche for swimming than the living tissue that biotrophic bacteria face. Another possibility is that, in gram-negative biotrophic pathogens, the Hrp-TTSS, which is generally a pathogenicity determinant, must be initiated after contact with host cells. As mentioned, such activation could result in downregulation of the flagellar system. In contrast, in most soft-rot necrotrophic phytopathogenic bacteria, the Hrp-TTSS serves mainly as a virulence rather than a pathogenicity determinant (Collmer and Keen 1986; Rantakari et al. 2001), and, therefore, can be downregulated for the benefit of the flagellar system, while disease can still take place. However, it is also possible that the roles played by flagella inside host tissue are, in some cases, more difficult to uncover, especially in artificial inoculation methods with high bacterial concentrations. In support of this possibility, although most cells of the biotrophic pathogen $R$. solanacearum tend to lose their flagella in planta, approximately $5 \%$ of the cells still remain motile (Tans-Kersten et al. 2001), implying that there must be a biological advantage for maintaining a certain amount of motile cells inside the host tissue.

Here, we showed that $A$. citrulli seems to behave in a different manner than $R$. solanacearum and other studied biotrophic
A

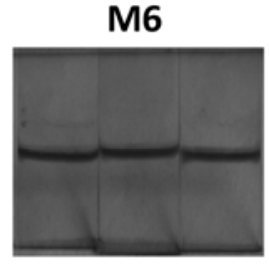

B

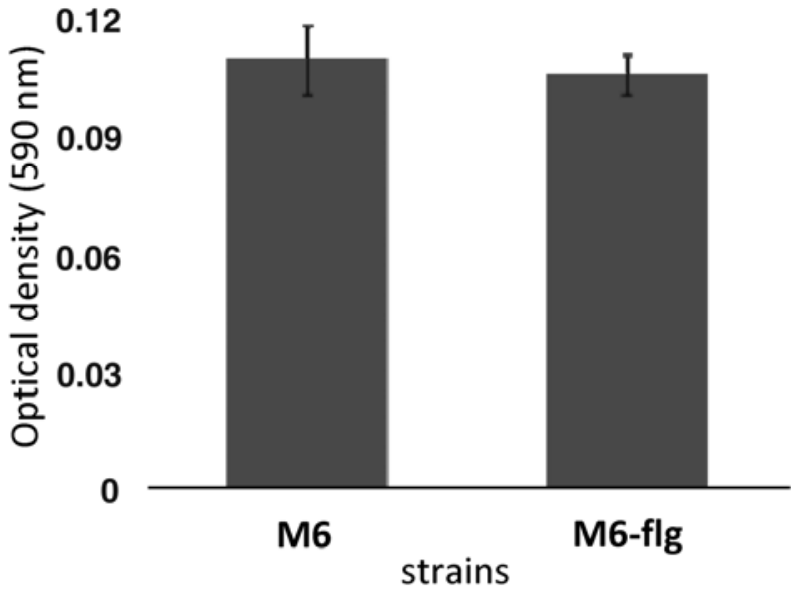

M6-flg

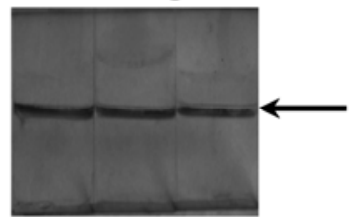

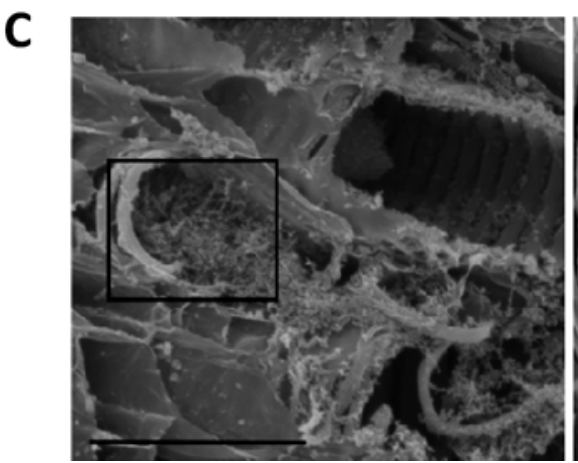

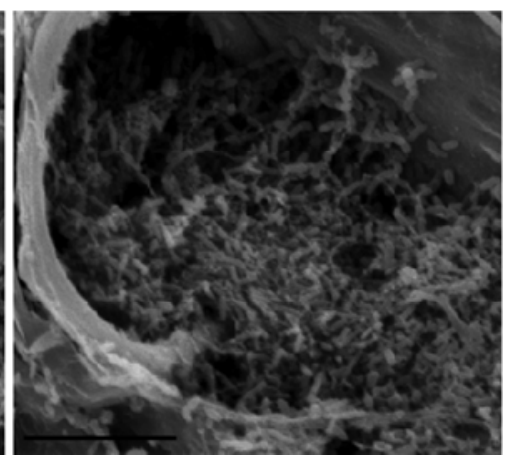

Fig. 7. Biofilm formation of Acidovorax citrulli M6 and M6-flg on glass slides and polystyrene plates. A, Biofilm formed at the air-medium interface on microscope glass slides were stained with $0.1 \%$ crystal violet (black arrow). B, Quantitative assessment of biofilm formed in polystyrene culture plates. Biofilm formed on culture plates were stained with $0.1 \%$ crystal violet and then resuspended with $200 \mu \mathrm{lof} 96 \%$ ethanol. The optical density at $590 \mathrm{~nm}$ of the resulting suspension was measured in a spectrophotometer. Differences between M6 and M6-flg were not significant $(P=0.05)$. Data (mean \pm standard error) from one experiment out of three with similar results. C, Scanning electron microscopy of stem tissue of M6-flg-inoculated melon seedlings. Pictures were taken 9 days after inoculation. Picture at the right (bar, $10 \mu \mathrm{m}$ ) is a magnification of the marked area in the left picture (bar, $50 \mu \mathrm{m})$. 
plant-pathogenic bacteria. First, polar flagella were shown to be important for virulence of $A$. citrulli also after tissue penetration in different pathogenicity assays. Second, we showed that most $A$. citrulli wild-type cells extracted from the melon xylem sap retain flagellum-mediated motility, implying that polar flagella and motility are important determinants of systemic infection by $A$. citrulli, at least in melon seedlings. However, it is important to stress that the assay used to extract bacteria from the xylem sap takes into account only bacterial cells that are not attached to and forming biofilm on the surface of the xylem vessels. Formation of $A$. citrulli biofilms adhered to xylem surfaces of melon seedlings was previously inferred (Bahar et al. 2009) and was strengthened in this study by the finding that, in seedlings from which only small amounts of sap could be extracted, high bacterial concentrations were detected. It is reasonable to hypothesize that high cell concentrations in the sap are associated with intense biofilm formation inside xylem vessels, which leads to xylem sap blockage and, eventually, to seedling wilt.

It is important to distinguish between the contribution of polar flagella to A. citrulli virulence in the vascular system and in the leaf tissue, because these niches are different from each other in their structural, chemical, and molecular properties. Inside the vascular system, the role of polar flagella is probably related to the ability of the bacterium to spread and, subsequently, adhere to and colonize the xylem walls. This was strongly supported by the fact that xylem sap from stem-inoculated seedlings showed significantly higher amounts of wildtype cells than polar flagellum mutants. In addition, bacterial counts from infected seedlings in stem inoculation assays revealed that, whereas no significant differences were found between the wild type and the polar flagellum mutant at the site of inoculation, the wild type showed a significantly increased ability to colonize the vascular tissues at more distant parts relative to the inoculation site. Similar to other pathogenic bacteria (Sigee 1993 ; Tans-Kersten et al. 2001; Tarbah and Goodman 1987) and conidia of vascular-pathogenic fungi (Mandeel 2006; Sewell and Wilson 1964), once inside the vascular tissue, cells of the A. citrulli polar flagellum mutant can travel passively to distant parts of infected vessels via the $x y-$ lem sap stream. However, polar flagella may be necessary for effective secondary colonization of new niches in the infected vessels and for vessel-to-vessel movement, which would allow the pathogen to gain entrance to xylem vessels that were not infected at inoculation. The contribution of polar flagella to these features could be either by direct effects or indirectly, through interactions with other virulence and pathogenicity determinants (discussed below).

Importantly, assessment of in planta growth following stem inoculation revealed that the polar flagellum mutant does retain the ability to colonize the upper portions of the seedling stem. In fact, this process was delayed in the mutant strain relative to the wild type by only a few days. Yet, the polar flagellum mutant was not able to induce increased seedling death as the wild type did, even at later stages of infection. We hypothesize that the observed differences in seedling death induction between the mutant and the wild type are due, at least in part, to the fact that the level of susceptibility of the seedlings decreases with time. Thus, by the time the polar flagellum mutant reaches high cell concentrations in the stem, the seedlings have become more tolerant to the infection and, therefore, may show disease symptoms but will not die. This hypothesis is supported by the fact that inoculation of the wild type into 10- to 12-day-old (and older) melon seedlings by the same method do not lead to seedling death (unpublished results), in contrast to inoculation of 8-day-old seedlings, as shown in this study. In agreement with this hypothesis is also the fact that seedling death is not a widespread phenomenon when melon plantlets are produced from contaminated seed lots in commercial nurseries.

In foliage infection, it is expected that polar flagellum-mediated motility contributes to accessing penetration sites, especially under high humidity, as was shown for other biotrophic bacteria (Hattermann and Ries 1989; Panopoulos and Schroth 1974; Taguchi et al. 2010). In our study, the reduced bacterial populations observed for the A. citrulli polar flagellum mutant relative to the wild type following foliage inoculation without vacuum could also be due to negative effects of the mutation on epiphytic survival. However, the mutant was clearly impaired in symptom induction ability and growth in planta, also following vacuum infiltration. In this case, one must wonder whether motility per se confers an advantage to the bacterium or, alternatively, is it about a different role played by polar flagella? It is possible that polar flagella also facilitate the attachment of the pathogen to the host cells. In addition, movement within the intercellular space could also be important for bacterial spread, because the apoplastic fluid could serve as a swimming medium. This seems likely when considering the low inoculum concentration that was used in vacuum inoculations $\left(10^{2} \mathrm{CFU} / \mathrm{ml}\right)$. Indeed, bacterial extractions done $2 \mathrm{~h}$ after inoculation revealed that, at this time, there are only a few hundreds of cells per gram of leaf. Under these conditions, wild-type cells could have a clear advantage over polar flagellum mutants, because swimming motility may facilitate spreading and further colonization of the leaf apoplast. This is also true for the stem inoculation assays because, despite using a high bacterial concentration, the inoculation technique and the removal of the inoculation droplet after inoculation in some of the experiments led to the introduction of relatively low numbers of bacteria into the stem. The use of high inoculum concentrations in virulence assays may explain why most studies with biotrophic plant-pathogenic bacteria have not identified roles for polar flagella after tissue penetration.

An interesting finding from this study was the negative impact of polar flagellum impairment on T4P-mediated twitching motility. This could also contribute to the reduced virulence of the polar flagellum mutants because, in A. citrulli, twitching ability is required for wild-type levels of virulence (Bahar et al. 2009). Under in vitro conditions, mutant M6-flg was not impaired in surface adhesion or biofilm formation, two features that were previously shown to require T4P. However, we also showed that the polar flagellum mutant does produce T4P. It is possible that the mere presence of T4P, even with reduced twitching ability, can facilitate attachment and biofilm formation, as was previously seen in MFC with the A. citrulli pilT mutant, which is hyperpiliated but lacks twitching motility (Bahar et al. 2010). Indeed, in those MFC studies, mutant M6flg did not appear to be impaired in biofilm formation relative to the wild type (Bahar et al. 2010), a notion that was strengthened in the present study by classical biofilm formation assays. Moreover, SEM observations of infected melon stems revealed that, despite being reduced in its colonization of the vascular tissue, the polar flagellum mutant still retains the ability to form biofilm on the surface of xylem vessels.

An important question to consider to further understand the role played by polar flagellum in virulence of $A$. citrulli is whether there is some kind of interaction between its regulation and that of other pathogenicity or virulence determinants of this pathogen, as observed in other pathogenic bacteria. HR assays on non-host tomato revealed no differences in HR induction between the wild type and polar flagellum mutants, suggesting that the latter are not affected in hrp gene expression. However, HR assays may not be sufficiently sensitive to detect subtle differences in hrp gene expression. In addition, 
even if the strains do not differ in this feature in a non-host plant, they may differ in the host. We are currently optimizing techniques to assess $A$. citrulli gene expression in planta in order to allow such questions to be addressed.

In summary, in addition to T4P, polar flagella contribute to A. citrulli virulence, playing an important role at both initial and later stages of infection of different plant tissues. Some kind of co-regulation may exist between the two types of motility (swimming and twitching) mediated by these two organelles. The fact that impairment of polar flagella in A. citrulli negatively affects twitching motility supports this hypothesis, as does our previous report that the T4P-null A. citrulli pilM mutant showed faster swimming motility and the hyperpiliated pilT mutant did not swim at all (Bahar et al. 2009). Further research should be done not only to understand how polar flagella and T4P "talk" with each other but also to identify the relative contributions to virulence of swimming and twitching motility and other phenotypes influenced by these organelles.

\section{MATERIALS AND METHODS}

Bacterial strains, plant material, and growth conditions.

A. citrulli strains used in this study are described in Table 1. Strains were routinely grown at $28^{\circ} \mathrm{C}$ on NA (Difco Laboratories, Detroit) or NB (Difco Laboratories), supplemented with kanamycin at $50 \mu \mathrm{g} / \mathrm{ml}$ or gentamicin $(\mathrm{Gm})$ at $20 \mu \mathrm{g} / \mathrm{ml}$, if required. For plant inoculation, strains were grown on NA with corresponding antibiotics (when suitable) for $48 \mathrm{~h}$ and then resuspended from plates using $10 \mathrm{mM} \mathrm{MgCl}_{2}$ with $0.045 \%$ silwet. Bacterial suspensions were adjusted using a Helios Gamma spectrophotometer (Thermo Electron Corp., Rochester, NY, U.S.A) and inocula were brought to the desired concentration by serial dilutions. Inoculum concentrations were verified by dilution plating. In some experiments, M9 minimal media (Sambrook et al. 1989) was used, with sodium citrate as carbon source and casamino acids at a final concentration of $0.7 \%$. For pathogenicity assays, melon (Cucumis melo) 'Ophir' (Zeraim Gedera, Gedera, Israel) seed or seedlings were used. Plants were grown in either sand or in a commercial soil mixture containing $50 \%$ peat, $30 \%$ tuff, $20 \%$ compost, and osmocote at $2 \mathrm{~kg} / \mathrm{m}^{3}$ (Shacham Givat Ada, Givat Ada, Israel) and maintained in a greenhouse at 25 to $28^{\circ} \mathrm{C}$.

\section{Construction of a flagellin-complemented strain.}

To create a complemented strain for the M6-flg mutant (Bahar et al. 2010), the M6 fliC gene (GenBank HQ878435) was polymerase chain reaction (PCR) amplified from genomic DNA of this strain using primers flgComp-F, GCCGGATCC CCTTC GCCACCAGCGGCAAA and flgComp-R, GCCTCTAGAGG CGGAACTCCTGCGAGGCT (underlined nucleotides represent restriction sites of $B a m \mathrm{HI}$ and $X b a \mathrm{I}$, respectively) and cloned into pTZ57R/T (Fermentas, Burlington, Canada). The amplified region contains the $f l i C$ open reading frame and 333 bp upstream of the start codon with its native promoter. The resulting plasmid, pTZ/flg-comp, was propagated in Escherichia coli $\mathrm{DH} 5 \alpha$, extracted with the GenElute plasmid miniprep kit (Sigma-Aldrich, St. Louis), and sent for sequencing at Hy Laboratories Ltd. (Rehovot, Israel). The flg-comp fragment was then excised from pTZ/flg-comp using restriction enzymes $B a m \mathrm{HI}$ and $\mathrm{XbaI}$ and subcloned into pBBR-MCS-5 (Kovach et al. 1995) that was predigested with the same enzymes. The resulting complementation plasmid (pBBR-MCS/flg-comp) was electroporated into E. coli S17-1 $\lambda$ pir (Simon et al. 1983), which was used to move it into strain M6-flg by biparental mating as described (Bahar et al. 2009). Transformants were selected on the basis of $\mathrm{Gm}$ resistance and verified by PCR and miniprep. One confirmed strain, named M6-flgComp, was selected for further studies.

\section{Seed transmission assays.}

Seed transmission assays were performed as described (Bahar et al. 2009). Briefly, 25 melon seeds were placed in $10^{6}-\mathrm{CFU} / \mathrm{ml}$ bacterial suspensions and incubated at room temperature for $2 \mathrm{~h}$ with gentle agitation. Seed were then passed through a strainer, washed briefly with sterile distilled water (SDW), and dried under a laminar flow hood. Seed were then sown in 600-ml pots (five or six seeds per pot and at least four pots per treatment) containing sand, or used to assess adhesion to seed as described (Bahar et al. 2009). Symptoms of emerging seedlings were visually evaluated at 10 dai.

\section{Stem inoculation assays.}

Melon seedlings were grown in a commercial soil mixture (as described above) for 8 days and then inoculated by placing a 5 - $\mu$ l droplet of bacterial suspensions at $10^{8}$ or $5 \times 10^{8}$ $\mathrm{CFU} / \mathrm{ml}$ at the base of the stem. Then, a 25 -gauge needle was passed through the droplet and the stem. In some experiments, the inoculum droplet was left until drawn as accepted for such kind of assays (Hill and Purcell 1995) whereas, in others, the inoculum droplet was removed immediately after needle injection with a paper towel. Inoculated seedlings were kept in the greenhouse and the percentage of wilting seedlings was evaluated every day until 12 to 14 dai. To assess bacterial concentrations in stem tissue at different time points, seedlings were collected and $1-\mathrm{cm}$ stem pieces around the inoculation site were taken and homogenized inside $10-\mathrm{mM} \mathrm{MgCl}_{2}$ suspensions, which were serially diluted and plated on NA plates. In addition, $1-\mathrm{cm}$ pieces were collected from the upper part of the seedling stems (at a distance of $4 \mathrm{~cm}$ from the bottom sample). At each time, five or six replicates were collected from each treatment. To assess bacterial concentration in xylem saps, inoculated stems were cut below the cotyledon stem joint and xylem sap was collected from the cut stem. Xylem saps were serially diluted and plated onto NA plates to determine cell concentration. Xylem fluids were also examined immediately under an Olympus BX51 microscope (Olympus, Center Valley, PA, U.S.A.) using a hemacytometer to determine the percentage of motile cells.

Table 1. Acidovorax citrulli strains used in this study

\begin{tabular}{|c|c|c|}
\hline Strain & Characteristics $^{\mathbf{a}}$ & Source or reference \\
\hline M6 & Group I wild-type strain, isolated from a melon fruit in Israel. & Burdman et al. 2005 \\
\hline M6-fliR & $\begin{array}{l}\text { An M6, nonmotile, transposon mutant strain, carrying a } \mathrm{Km}^{\mathrm{r}} \text { cassette within the fliR open } \\
\text { reading frame. }\end{array}$ & This study \\
\hline M6-flg & $\begin{array}{l}\text { M6 insertional mutant impaired in } f l i C \text {, encoding the flagellin subunit }\left(\mathrm{Km}^{\mathrm{r}}\right) \text {. This strain is } \\
\text { nonmotile and flagellum-naked. }\end{array}$ & Bahar et al. 2010 \\
\hline M6-Aave_4401 & $\begin{array}{l}\text { M6 insertional mutant impaired in the } f l i C \text {-like gene (Aave_ } 4401 \text { according to the annotation } \\
\text { AXof strain AAC00-1) }\left(\mathrm{Km}^{\mathrm{r}}\right) \text {. This strain produces polar flagellum and is motile. }\end{array}$ & This study \\
\hline M6-flgComp & $\begin{array}{l}\text { M6-flg containing plasmid pBBR-MCS/flg-comp, which restores flagellum production and } \\
\text { swimming motility }\left(\mathrm{Km}^{\mathrm{r}}, \mathrm{Gm}^{\mathrm{r}}\right) \text {. }\end{array}$ & This study \\
\hline
\end{tabular}

${ }^{\mathrm{a}} \mathrm{Km}^{\mathrm{r}}$ and $\mathrm{Gm}^{\mathrm{r}}$ indicate kanamycin and gentamicin resistance, respectively. 
Foliage inoculation assays.

For vacuum infiltration, seedlings with three true leaves were immersed inside a $10^{2}-\mathrm{CFU} / \mathrm{ml}$ bacterial suspension placed inside a vacuum chamber. Pressure was applied at 600 mbar and maintained for $50 \mathrm{~s}$. Seedlings were then placed in the greenhouse and allowed to dry. Then, $2 \mathrm{~h}$ later, first samples were taken for assessment of bacterial concentration inside the leaf tissue at time zero. Each replicate was composed of 12 leaf discs ( $7 \mathrm{~mm}$ in diameter each) that were taken from the first three true leaves (4 discs from each leaf) of each plant. In each sampling time and for each treatment, five plants were sampled. Leaf discs were homogenized inside a $10-\mathrm{mM} \mathrm{MgCl}$ suspension, serially diluted, and plated on NA plates. Samplings were performed at various time points after inoculation. For foliage inoculation without vacuum, melon seedlings at the same developmental stage were immersed inside a $10^{6}$. $\mathrm{CFU} / \mathrm{ml}$ bacterial suspension for $3 \mathrm{~min}$, and then either placed in the greenhouse under normal conditions or placed under a high-humidity regime (above 90\%) for $24 \mathrm{~h}$ and then under regular conditions. Sampling of leaf tissues for assessment of bacterial concentration was done as described for vacuum inoculation. HR assays were performed by syringe infiltration (without a needle) of bacteria at various concentrations into the abaxial side of 5-week-old tomato (Solanum lycopersicum) 'Hawaii H7998' (Yu et al. 1995). HR was visualized 24 and 48 hai.

\section{Flagellin purification and sodium dodecyl sulfate polyacrylamide gel electrophoresis.}

A. citrulli strains were grown in $200 \mathrm{ml}$ of NB until the late $\log$ phase. Cells were then collected by centrifugation at $3,800 \times g$ for $15 \mathrm{~min}$ using a precooled $\left(4^{\circ} \mathrm{C}\right)$ Sorvall centrifuge (Sorvall, Braintree, MA, U.S.A.). The supernatant was discarded and bacterial pellets were resuspended with $50 \mathrm{ml}$ of sodium phosphate buffer ( $50 \mathrm{mM}$ sodium phosphate and 10 $\mathrm{mM} \mathrm{MgCl} 2, \mathrm{pH}$ 7). Resuspended cells were blended for $20 \mathrm{~s}$ inside a Waring commercial blender (Torrington, CT, U.S.A.) to shear off flagella. Cells were separated from flagella by centrifugation at $12,000 \times g$ for $30 \mathrm{~min}$. The supernatant was collected and flagella were pelleted by centrifugation at 100,000 $\times g$ for $50 \mathrm{~min}$ using a Sorvall WX 90 ultracentrifuge. Pellets containing flagella were resuspended using $1 \mathrm{ml}$ of sodium phosphate buffer. The samples were run in sodium dodecyl sulfate polyacrylamide gel electrophoresis (12\% acrylamide) at $20 \mathrm{~mA}$ for $2.5 \mathrm{~h}$ and stained with Coomassie brilliant blue by standard methods (Sambrook et al. 1989).

\section{Electron microscopy.}

TEM was used to visualize T4P and polar flagella of bacteria grown in culture. SEM was used to visualize bacterial cells in plant xylem vessels following stem inoculation assays. Specimens for both TEM and SEM were prepared as previously described (Bahar et al. 2009).

\section{Swimming, twitching, and biofilm formation assays.}

Swimming assays were performed as described by Bahar and associates (2009). Briefly, 48-h-old A. citrulli colonies were stab inoculated onto the middle of $0.3 \%$ agar NA plates, which were then kept at $28^{\circ} \mathrm{C}$. Swimming haloes were measured 48 hai. For twitching motility assays, A. citrulli cells were collected from 48-h-old NA plates with SDW, serially diluted, and plated onto fresh NA plates. The length of twitching haloes around colonies was measured 48 and $72 \mathrm{~h}$ after plating on plates where the number of colonies ranged from 100 to 200 , using a Nikon Eclipse $80 \mathrm{i}$ microscope $(\times 100$ magnification) and the NIS elements software (Nikon, Tokyo). For each colony, four lengths were measured to determine the average twitching zone length. For each strain, the average halo length of a minimum of 12 colonies was measured at each time point. Classical in vitro biofilm assays were performed using microscope glass slides or polystyrene 24-well multidishes (Nunc, Roskilde, Denmark) as described (Bahar et al. 2009).

\section{Statistical analysis.}

All assays were conducted at least twice. In assays where statistical significance is mentioned, the Tukey-Kramer honestly significant difference test for mean comparison was applied using the JMP software (SAS Institute Inc., Cary, NC, U.S.A.).

\section{ACKNOWLEDGMENTS}

We thank N. Bahat and V. Holdengreber for technical assistance in scanning and transmission electron microscopy, respectively; and Y. Helman for valuable comments during the preparation of the manuscript. This project was partially funded by grant number 823018005 from the Chief Scientist of the Israeli Ministry of Agriculture.

\section{LITERATURE CITED}

Akerley, B. J., Cotter, P. A., and Miller, J. F. 1995. Ectopic expression of the flagellar regulon alters development of the Bordetella-host interaction. Cell 80:611-620.

Antunez-Lamas, M., Cabrera-Ordonez, E., Lopez-Solanilla, E., Raposo, R., Trelles-Salazar, O., Rodriguez-Moreno, A., and RodriguezPalenzuela, P. 2009. Role of motility and chemotaxis in the pathogenesis of Dickeya dadantii 3937 (ex Erwinia chrysanthemi 3937). Microbiology 155:434-442.

Bahar, O., and Burdman, S. 2010. Bacterial fruit blotch: A threat to the cucurbit industry. Isr. J. Plant Sci. 58:19-31.

Bahar, O., Goffer, T., and Burdman, S. 2009. Type IV pili are required for virulence, twitching motility, and biofilm formation of Acidovorax avenae subsp. citrulli. Mol. Plant-Microbe Interact. 22:909-920.

Bahar, O., De La Fuente, L., and Burdman, S. 2010. Assessing adhesion, biofilm formation and motility of Acidovorax citrulli using microfluidic flow chambers. FEMS (Fed. Eur. Microbiol. Soc.) Microbiol. Lett. 312:33-39.

Bayot, R. G., and Ries, S. M. 1986. Role of motility in apple blossom infection by Erwinia amylovora and studies of fire blight control with attractant and repellent compounds. Phytopathology 76:441-445.

Burdman, S., Kots, N., Kritzman, G., and Kopelowitz, J. 2005. Molecular, physiological, and host-range characterization of Acidovorax avenae subsp. citrulli isolates from watermelon and melon in Israel. Plant Dis. 89:1339-1347.

Collmer, A., and Keen, N. T. 1986. The role of the pectic enzymes in plant pathogenesis. Annu. Rev. Phytopathol. 24:383-409.

Fan, F., Ohnishi, K., Francis, N. R., and Macnab, R. M. 1997. The FliP and FliR proteins of Salmonella typhimurium, putative components of the type III flagellar export apparatus, are located in the flagellar basal body. Mol. Microbiol. 26:1035-1046.

Feng, T. Y., and Kuo, T. T. 1975. Bacterial leaf blight of rice plant .VI. Chemotactic responses of Xanthomonas oryzae to water droplets exudated from water pores on leaf of rice plants. Bot. Bull. Acta Sin. 16:126-136.

Guerry, P., Alm, R. A., Power, M. E., Logan, S. M., and Trust, T. J. 1991. Role of two flagellin genes in Campylobacter motility. J. Bacteriol. 173:4757-4764.

Hattermann, D. R., and Ries, S. M. 1989. Motility of Pseudomonas syringae pv. glycinea and its role in infection. Phytopathology 79:284-289.

Hill, B. L., and Purcell, A. H. 1995. Multiplication and movement of Xylella fastidiosa with grapevine and four other plants. Phytopathology 85:1368-1372.

Hueck, C. J. 1998. Type III protein secretion systems in bacterial pathogens of animals and plants. Microbiol. Mol. Biol. Rev. 62:379-433.

Ichinose, Y., Shimizu, R., Ikeda, Y., Taguchi, F., Marutani, M., Mukaihara, T., Inagaki, Y., Toyoda, K., and Shiraishi, T. 2003. Need for flagella for complete virulence of Pseudomonas syringae pv. tabaci: Genetic analysis with flagella-defective mutants $\Delta$ fliC and $\Delta$ fliD in host tobacco plants. J. Gen. Plant Pathol. 69:244-249.

Josenhans, C., and Suerbaum, S. 2002. The role of motility as a virulence factor in bacteria. Int. J. Med. Microbiol. 291:605-614.

Josenhans, C., Labigne, A., and Suerbaum, S. 1995. Comparative ultrastructural and functional-studies of Helicobacter pylori and Helicobacter mustelae flagellin mutants: Both flagellin subunits, FlaA and $\mathrm{FlaB}$, are necessary for full motility in Helicobacter species. J. Bacteriol. 177:3010-3020 
Kovach, M. E., Elzer, P. H., Hill, D. S., Robertson, G. T., Farris, M. A., Roop, R. M., II., and Peterson, K. M. 1995. Four new derivatives of the broad-host-range cloning vector pBBR1MCS, carrying different antibiotic-resistance cassettes. Gene 166:175-176.

Lee, M. C., Weng, S. F., and Tseng, Y. H. 2003. Flagellin gene fliC of Xanthomonas campestris is upregulated by transcription factor Clp. Biochem. Biophys. Res. Commun. 307:647-652.

Macnab, R. M. 1999. The bacterial flagellum: Reversible rotary propeller and type III export apparatus. J. Bacteriol. 181:7149-7153.

Macnab, R. M. 2003. How bacteria assemble flagella. Annu. Rev. Microbiol. 57:77-100

Mandeel, Q. A. 2006. Influence of plant root exudates, germ tube orientation and passive conidia transport on biological control of Fusarium wilt by strains of nonpathogenic Fusarium oxysporum. Mycopathologia 161:173182.

Manson, M. D., Armitage, J. P., Hoch, J. A., and Macnab, R. M. 1998. Bacterial locomotion and signal transduction. J. Bacteriol. 180:1009-1022.

Moens, S., and Vanderleyden, J. 1996. Functions of bacterial flagella. Crit. Rev. Microbiol. 22:67-100.

Mulholland, V., Hinton, J. C. D., Sidebotham, J., Toth, I. K., Hyman, L. J., Perombelon, M. C. M., Reeves, P. J., and Salmond, G. P. C. 1993. A pleiotropic reduced virulence (Rvi-) mutant of Erwinia carotovora subspecies atroseptica is defective in flagella assembly proteins that are conserved in plant and animal bacterial pathogens. Mol. Microbiol. 9:343-356.

Ottemann, K. M., and Miller, J. F. 1997. Roles for motility in bacterialhost interactions. Mol. Microbiol. 24:1109-1117.

Panopoulos, N. J., and Schroth, M. N. 1974. Role of flagellar motility in the invasion of bean leaves by Pseudomonas phaseolicola. Phytopathology 64:1389-1397.

Pirhonen, M., Saarilahti, H., Karlsson, M. B., and Palva, E. T. 1991. Identification of pathogenicity determinants of Erwinia carotovora subsp. carotovora by transposon mutagenesis. Mol. Plant-Microbe Interact. 4:276-283.

Pleier, E., and Schmitt, R. 1989. Identification and sequence-analysis of two related flagellin genes in Rhizobium meliloti. J. Bacteriol. 171:1467-1475.

Rantakari, A., Virtaharju, O., Vähämiko, S., Taira, S., Palva, E. T., Saarilahti, H. T., and Romantschuk, M. 2001. Type III secretion contributes to the pathogenesis of the soft-rot pathogen Erwinia carotovora: Partial characterization of the hrp gene cluster. Mol. Plant-Microbe Interact. 14:962-968.
Sambrook, J., Fritsch, E. F., and Maniatis, T. 1989. Molecular Cloning: A Laboratory Manual. Cold Spring Harbor Laboratory Press, Cold Spring Harbor, NY, U.S.A.

Schaad, N. W., Postnikova, E., and Randhawa, P. S. 2003. Emergence of Acidovorax avenae subsp. citrulli as a crop threatening disease of watermelon and melon. Pages 573-581 in: Pseudomonas syringae and Related Pathogens. N. S. Iacobellis, A. Collmer, S. W. Hutcheson, J. W. Mansfield, C. E. Morris, J. Murillo, N. W. Schaad, D. E. Stead, G. Surico, and M. S. Ullrich, eds. Kluwer Academic Publishers, Dordrecht, The Netherlands.

Schaad, N. W., Postnikova, E., Sechler, A., Claflin, L. E., Vidaver, A. K. Jones, J. B., Agarkova, I., Ignatov, A., Dickstein, E., and Ramundo, B. A. 2008. Reclassification of subspecies of Acidovorax avenae as A. avenae (Manns 1905) emend., A. cattleyae (Pavarino, 1911) comb. nov., A. citrulli Schaad et al. 1978) comb. nov., and proposal of A. oryzae sp nov. Syst. Appl. Microbiol. 31:434-446.

Sewell, G. W. F., and Wilson, J. F. 1964. Occurrence and dispersal of Verticillium conidia in xylem sap of the hop (Humulus lupulus L.). Nature 204:901.

Sigee, D. C. 1993. Bacterial Plant Pathology. Cell and Molecular Aspects. Cambridge University Press, Cambridge.

Simon, R., Priefer, U., and Puhler, A. 1983. A broad host range mobilization system for in vivo genetic engineering: Transposon mutagenesis in gram negative bacteria. Biotechnology 1:784-791

Taguchi, F., Yamamoto, M., Ohnishi-Kameyama, M., Iwaki, M., Yoshida, M., Ishii, T., Konishi, T., and Ichinose, Y. 2010. Defects in flagellin glycosylation affect the virulence of Pseudomonas syringae pv. tabaci 6605 Microbiology 156:72-80.

Tans-Kersten, J., Huang, H. Y., and Allen, C. 2001. Ralstonia solanacearum needs motility for invasive virulence on tomato. J. Bacteriol. 183:35973605 .

Tarbah, F., and Goodman, R. N. 1987. Systemic spread of Agrobacterium tumefaciens biovar 3 in the vascular system of grapes. Phytopathology 77:915-920.

Walcott, R. R., Fessehaie, A., and Castro, A. C. 2004. Differences in pathogenicity between two genetically distinct groups of Acidovorax avenae subsp. citrulli on cucurbit hosts. J. Phytopathol. 152:277-285.

Yu, Z. H., Wang, J. F., Stall, R. E., and Vallejos, C. E. 1995. Genomic localization of tomato genes that control a hypersensitive reaction to Xanthomonas campestris pv. vesicatoria (Doidge) Dye. Genetics 141:675682. 